\title{
The Socio-phonetics and Morphosyntax of Language Variation in Jordan
}

\author{
Othman Khalid Al Shboul \\ Jadara University \\ Irbid-Jordan
}

Received: January 28, 2021 Accepted: June 24, 2021 Published: June 28, 2021

doi:10.5296/jsel.v9i1.18817ＵRL: https://doi.org/10.5296/jsel.v9i1.18817

\begin{abstract}
This study investigates the linguistic choices made by the participants at the level of phonetics and morphosyntax in Irbid city. The study examines the way speakers reconstruct their new identity, as belonging to an upper social class rather than to their real middle class. The researcher assumed that he would find a lot of variation among the speakers in this city that is worth examining socio-linguistically, especially that Irbid is rich in linguistic variation and social contact. The data were extracted from the videos of ten field interviews. The researcher found that gender, age and education influence the way people speak. That is to say, the young people (both males and females) were more triggered to make linguistic changes than their aged counterparts. Besides, the females produced more vernacular variants than the males. This research attempts to investigate social class as an attraction, to which the speaker tries to reach, pushing him/her to make linguistic changes, rather than as a social factor affecting the speaker's choices since this study assumes that the speaker makes linguistic changes as he/she reconstructs his/her identity in the new social class (the attraction or target). The study concludes that social class, in particular, serves as a motivation factor that pushes speakers to reformulate their identity.
\end{abstract}

Keywords: Variation, Phonetics, Morphosyntax, Identity, Irbid City 


\section{Introduction}

The paper investigates language variation at two different linguistic levels: phonetics and morphosyntax in Jordanian Arabic as spoken by those who live in Irbid city. From a sociolinguistic perspective, the language variation investigated in the study carries not only a linguistic meaning but also a social meaning since linguistic variants that the participants (the people who speak in the videos viewed in YouTube in the study) produce serve as social markers that index a particular social class (positioning themselves in a higher social class). Accordingly, the study mainly investigates the way speakers reformulate their new identity, with considering gender, age and education as factors affecting the way people speak (since they play a role in pushing these speakers to make linguistic changes). Besides, this study investigates (upper) social class as a target to which the speaker tries to reach. Gender, age and education are social factors that affect the extent to which speakers make such changes. These social factors (gender, age and education) are linked with language variation that exists among speakers living in one society (Irbid city) on the assumption, made by many researchers (e.g. Labov, 2006; Wardhaugh \& Fuller, 2014), that a lot of variation is not only variety-specific, but also speaker-specific. The researcher, therefore, assumed that he would find a lot of variation among the speakers in this city that is worth examining socio-linguistically, especially that Irbid is one of the biggest Jordanian cities that is rich in dialects and social contact. Before the researcher conducted the research, the researcher hypothesized that the educated young people (both males and females) are more triggered to make linguistic changes than their aged counterparts. Also, the researcher hypothesized that the females produce more vernacular variants than the males in Irbid city.

\section{Literature Review}

Many researchers (e.g. Cotter, 2016; Podesva, 2006) maintain that sociophonetics/ sociophonology is relatively a new field; it emerged due to the fact that phonetics and phonology do not account for the variation governed or conditioned by non-linguistic factors. That is, while it is true that most phonetic and phonemic changes are linguistically governed, and hence their occurrence is conditioned on the availability of specific linguistic environments, other changes, in turn, that occur at the same (phonetic or phonemic) level, cannot be explained or justified by the same (linguistic) reasons. That is, there are other factors (non-linguistic) that are responsible for these changes. Accordingly, sociolinguistic motives are investigated as an important resource to explain and justify such changes at two different linguistic levels (phonetics and morphosyntax) that the speakers make in the current study.

The linguistic variation at the level of phonetics and morphosyntax in Jordan is attributed to the fact that Jordanian society consists of various demographic, ethnic and social backgrounds. In this regard, Suleiman (1985) broadly divided Jordanian Arabic (JA) into three dialects: the Bedouin dialect, spoken by the non-sedentary nomads, the Fallahi dialect, in rural areas, and the Madani dialect, in the urban places. The predominant dialect used in 
Irbid city is Fallahi which is spoken by the middle-class people living in many cities in Jordan.

The study is, therefore, sociolinguistics-based, where language variation studies that investigate speakers' linguistic selection integrate many features and concepts from different linguistic levels with those that are mainly used in sociolinguistics. For example, Foulkes et al (2010) argue that sociophonetics draws on different concepts and frameworks from phonetics and sociolinguistics so that they complement one another. To put it another way, it is argued that while researchers investigate how speakers construct their identity at the linguistic (like phonetic) level, sociolinguistics provides justifications for and explanations of why speakers favor to use a one phonetic variant over the other. Accordingly, different factors are investigated and systematically connected with this phonetic variation employed by these speakers, revealing more clearly (and systematically) the relationship between language and society. In this regard, Kaiser (2011) maintains that this language variation is seen as knowledge that speakers, belonging to one community, have of their language and accent.

About the studies that investigate languages variation at the level of phonetics, Cotter (2016) investigates the different realizations of the phonological variable /q/ as used by residents (including also 7 refugees from Jaffans) in Gaza city. The researcher found that the uvular stop /q/ has three different linguistic realizations because of dialect contact among the indigenous residents of Gaza city with refugees from Jaffa city. These different linguistic realizations of /q/ are basically correlated with three social factors: dialect background, gender and age. Female speakers (Gazans and Jaffan) show far higher tendency to favor the glottal [?] realization over the [g] realization than their counterparts (male speakers). Thus, social information constitutes an important resource for investigating linguistic variation. In this respect, Labov (1972) (as cited in Hay and Drager, 2007) demonstrates that the frequency of production of particular variants systematically varies with three important factors. These factors are: social class, age, and speaker style. However, geographical background also plays no less important role than those factors in affecting speakers' linguistic choice. For example, Sebregts (2015) found in his data analysis a wide range of the phonological $/ \mathrm{r} /$ variable in Dutch, reaching twenty variants produced by people in different places in the country.

At a higher level of linguistic changes (such as morphosyntactic change), Tucker (2011) reports that the morpheme (such as suffixes) in Arabic verbs has different cognate particles in other dialects of Arabic spoken in different countries in the Arab world. However, across all those Arabic dialects, the common meaning to these cognates is of a habitual aspect. That is, they do not have any lexical meaning but they reflect or index some social meaning. Furthermore, Embick (2008) discusses the complementary distribution of morphosyntactic variants. That is, when a speaker favors to use one variant over the other in one situation, it means that the other variant of the same variable is not used in that situation where that (the first) variant was produced. Thus, he asserts the idea that these (distinct) variants compete with one another, and therefore it is only social motives that can justify and account for this distribution. 


\section{Purpose of the Study}

This study investigates social class as motive for the speaker to make phonetic and morphosyntactic changes while gender, age and education influence to what extent the speaker can make these changes as they reformulate their identity in the new social class. To the best of my knowledge, no study has been conducted so far to investigate the language variation that exists in Irbid city. The researcher, therefore, investigates language variation in the city at the phonetic and morphosyntactic level combined. The present study aims at investigating particular phonetic and morphosyntactic variants (alveolar stops in phonetics; negation construction in morphosyntax) as used by the participants (the speakers in the videos viewed). These phonetic and morphosyntactic changes are seen as contributors to reformulating Jordanian speakers' social identities in the city. Simply put, the researcher examined three social variables (gender, age and education) that play a role in pushing speakers one way or another to adopt a new identity that belongs to the upper social class which is at the top of the social hierarchy of the Jordanian people.

\section{Delimitation of the Study}

Although there are many aspects of linguistic variations characterizing speakers' dialects in Irbid city that can be investigated, the study is limited to only investigate alveolar stops at the level of phonetics and negation at the level of morphosyntax. In addition, this study did not apply any software program to track and analyze the detailed properties of variants, especially those at the level of phonetics. It is confined to one method of data collection, which is YouTube.

\section{Research Questions}

From a sociolinguistic perspective, the researcher tried to answer the following questions by investigating some phonetic and morphosyntactic variants as social markers (alveolar stops and negation construction in Jordanian Arabic) that are not linguistically but socially-governed.

1. To what extent do gender, age and education as social factors affect the participants' (the interviewees') phonetic and morphosyntactic choice for the purpose of reconstructing a new social identity as high social class speakers in Jordan?

2. Who have more tendencies to make linguistic changes: Are they females or males?

3. Who produce variants that are less standard (more vernacular): Are they females or males?

\section{Data Collection and Methodology}

For the data of this study, the researcher collected the data from You Tube rather than administering face-to-face interviews made specifically for linguistics analysis research 
purposes. This is because speakers are less likely to change the way they speak than they do in interviews designed specifically for linguistic analysis research, whose aim is to track speakers' language and how they speak, as participants are aware that the language they use will be investigated. Accordingly, this guarantees that people communicate more naturally, and hence the data obtained is more authentic.

The researcher transcribed and extracted the desired data from the people speaking in these videos. In these videos, I found a variety of sociolinguistic variables that are worth investigating. The researcher viewed ten YouTube videos, as shown in the table (1) below, from which he collected the data. The researcher tried to extract the data from the videos of field interviews because in such programs people are first asked to introduce themselves so that he can use this information to analyze the data in terms of the three investigated social factors (gender, age and education).

Table 1. The videos viewed for the study.

\begin{tabular}{|l|l|l|l|l|l|}
\hline NO & $\begin{array}{l}\text { Length of } \\
\text { recording }\end{array}$ & Date & $\begin{array}{l}\text { Length of } \\
\text { recording }\end{array}$ & Date \\
\hline 1 & $13: 53$ & Apr 27, 2018 & 6 & $4: 10$ & Apr 24, 2018 \\
\hline 2 & $10: 22$ & Oct 27, 2015 & 7 & $2: 56$ & Mar 17, 2017 \\
\hline 3 & $19: 20$ & Sep 19, 2013 & 8 & $3: 31$ & Dec 25, 2015 \\
\hline 4 & $3: 13$ & Jan 5, 2015 & 9 & $3: 39$ & Aug 21, 2015 \\
\hline 5 & $16: 00$ & Mar 1, 2013 & 10 & $3: 46$ & Oct 18, 2014 \\
\hline
\end{tabular}

All these videos viewed are field interviews in which the interviewers and interviewees talk about some cultural social, educational or economic issues that concern Irbid city. The researcher chose YouTube videos as the best alternative method to audio and video recordings to collect spontaneous data from the participants, especially that there is much linguistic variety in the data collected, and thereby this makes this method much real interview. The researcher selected these ten videos on the basis that they involve ordinary people (the interviewees) from Irbid city, which is a city of a middle social class and the interviewers are from Amman city, which is a city of upper social class in order to uncover how people of the middle class (in Irbid city) speak, especially when interacting with people from the upper social class (such as the interviewers). Besides, these videos show many places in Irbid city where people were recorded so that the researcher can guarantee that all these interactions occurred in Irbid. Besides, because the researcher is originally from Irbid, it was easy for him to recognize the dialect spoken there and if the people in the videos are Irbidians. So, by this method, the researcher transcribed and extracted the desired data from the people speaking in a natural-like way as these videos analyzed are not originally designed or made for research purposes. In the analysis, the researcher included some extracts in which phonetic or morphosyntactic changes occur, explaining the social situation in which the participants were involved. For the data analysis, due to space limitations, the researcher did not use any statistics to count and compare the frequencies. Alternatively, the results were revealed in the form of ratio, such as half to half or one third to two thirds, and the like. 


\section{Data Analysis and Findings}

The variants in the tables below are classified as they are originally used by the middle-class and high-class people. For example, the [dh] variant as in haadha 'this' is produced by the middle-class people, like those who live in Irbid city (such as the interviewee) while the [d] variant as in haada 'this' is produced by the high-class people, like those who live in Amman city (such as the interviewer). But recently due to social contact between the two classes much more than before, many linguistic changes have been predominantly made by the middle-class people (like those in Irbid city) in an attempt to reconstruct their identity as high-class speakers by adopting new phonetic and morphosyntactic variants produced originally by the high-class people. In the study, the researcher did not analyze high-class variants as used by high-class people but as used by middle-class people that they produce to reformulate their identity in this (high) class. Accordingly, all the data in the study was extracted from the middle-class people.

Table 2. Phonetic variation among high and middle-class people in Jordan

\begin{tabular}{|c|c|c|c|c|}
\hline \multicolumn{5}{|c|}{ Phonetic variation (alveolar stops) } \\
\hline $\begin{array}{l}\text { Modern } \\
\text { Standard } \\
\text { variables }\end{array}$ & $\begin{array}{l}\text { Middle-class } \\
\text { variants }\end{array}$ & Examples & High-class variants & Examples \\
\hline$/ \mathrm{dh} /$ & {$[\mathrm{dh}]$} & $\begin{array}{l}\text { haadha } \\
\text { 'this' }\end{array}$ & {$[\mathrm{d}]$} & haada 'this' \\
\hline$/ \mathrm{T} /$ & {$[\mathrm{T}]$} & $\begin{array}{l}\text { Tayeb } \\
\text { 'Okay' }\end{array}$ & {$[\mathrm{t}]$} & tayeb 'Okay' \\
\hline
\end{tabular}

Table 3. Morphosyntactic variation among high and middle-class people in Jordan

\begin{tabular}{|c|c|c|c|c|}
\hline \multicolumn{4}{|c|}{ Morphosyntactic variation (negation) } & \multirow[b]{2}{*}{ Examples } \\
\hline $\begin{array}{l}\text { Modern } \\
\text { Standard } \\
\text { variables }\end{array}$ & $\begin{array}{l}\text { Middle-class } \\
\text { variants }\end{array}$ & Examples & High-class variants & \\
\hline $\begin{array}{l}\text { /maa+lexical } \\
\text { verb/ }\end{array}$ & $\begin{array}{l}{[\text { maa+lexical }} \\
\text { verb+ish] }\end{array}$ & $\begin{array}{l}\text { ma katabitish } \\
\text { 'I didn't write' }\end{array}$ & $\begin{array}{l}{[\text { lisa+maa+ lexical }} \\
\text { verb] }\end{array}$ & $\begin{array}{l}\text { lisa ma katabit } \\
\text { 'I didn't write' }\end{array}$ \\
\hline
\end{tabular}

The data show a lot of linguistic variation that can be realized in different aspects of speech in Irbid city. But, in the current research paper, the variants that the researcher investigated at the level of phonetics are alveolar stops and at the level of morphosyntax are negative particles. Accordingly, this section discusses these linguistic changes in two separate subsections: The first subsection is concerned with the phonetic changes (the socio-phonetics of alveolar stops) while the second subsection is concerned with the morphosyntactic changes 
(the socio-morphosyntax of negation). However, due to space limitation, the researcher will only give one example of each of the new variants examined in the study.

\subsection{Socio-phonetic Variation}

Example One:

A female teacher was interviewed by an interviewer in one of the TV programs to talk about the healthy food programs offered in the school in Irbid city where she is teaching. As indicated in the video, the interviewer is from the capital city (and therefore from a high socioeconomic class), and the teacher (the interviewee) is from the middle class and teaches at a primary school in Irbid city. However, this participant (the teacher) produces variants of a high social class rather than of (her original) middle social class at the phonetic level, as shown in the transcription below:

lamma tifel yrou7 3a 7amaam lazim yajkigh sabonah wkamaan yit3awdua 3 akil Si7i yd3ibuw ma3hum fawakih w khudaar.

"When the child goes to the bath, he/she should use soap. Besides, he/she should also eat healthy food particularly fruit and vegetables".

The teacher favored to use the [t] variant over the emphatic [T] counterpart in the word /tifel/, saying tifel 'a baby' rather than Tifel 'a baby' because [T] tends to be pharyngealized and emphatic, and hence avoided by most females as is considered to be less prestigious. As the data analysis shows, almost two thirds of the users of this variant $[t]$ are females, particularly the young, while the remaining third are male speakers. This finding agrees with Almbark's (2011) in that Syrian female speakers prefer to use the [t] variant to the [T] variant, as it is less emphatic than [T]. Another variant which is used by the same speaker is [d] as an alternative to the other emphatic sound [dh], saying khudaar 'vegetables' rather than khadhaar 'vegetables' even though this variant [dh] is originally used by the middle class (where the teacher is from). However, regarding the use of this variant [d], it differs from the $[\mathrm{t}]$ variant in that the $[\mathrm{t}]$ variant almost is not used by the males regardless of their age and education. This can be explained by that this [t] variant in Jordanian Arabic is more linked with femininity. As a consequence, males would be highly criticized if they speak very smoothly by using such a variant that indicates that they imitate females in the way they speak, and hence males try to avoid using this variant $[\mathrm{t}]$, as an alternative to the emphatic variant $[\mathrm{T}]$. In the data examined, the researcher did not find any male participant use this variant [t], as an alternative to the empathic [T].

Example Two:

Another example shows a man in forties talking about the prices before and after clearance, and if they are real sales.

ass3aar elbasTat bitkuun rakhisa la?inha bitkuun taSfiyi bdha3ihd ma7alaat.

"The prices of items here are much cheaper because they are on clearance from stores". 
The phonological variable /dh/ has two phonetic variants: [dh] and [d]. That is, while many young people of both genders produce the weakened version of the /dh/ variable, which is [d], other people particularly over forties have much more tendency to use the [dh] variant over the [d] variant than the young males and females. So, while the [dh] variant is considered to be more standard than the [d] variant, the data analysis indicates that females use more [d] than males in Irbid city. This is in contrast with what Romaine (2003) found that men tend to use less standard forms than their female counterparts (cited in Wardhaugh \& Fuller, 2014).

\subsection{Socio-morphosyntactic Variation}

Example Three:

The interviewer asks people about the appropriate age for marriage and if they should have a job first. One of the interviewees, who is from Irbid city said:

anna lisa maa tkharajit ba3idni bas mumkin lma akhalis akid ra7 adwir 3 aa shughil mubashraah 7 asa3id ahli w ba3din bafakir bizwaaj.

"I have not graduated yet. But when I graduate, I will immediately look for a job to help my family and then I will consider this matter (marriage)".

At the morphosyntactic level, this negation variant of upper social class [lisa maa tkharajit] 'I have not graduated' is used by a middle-class speaker who is a university student. The counterpart variant of this negation variant is [maa tkharajitish] which is of the middle class, but this variant [maa tkharajitish] was not used by the interviewee although he is from the middle class. So, what happened is that he adopted a new variant which is of the upper social class to reconstruct himself in this class rather than in his original class (the middle class), especially that the person (the interviewer) whom he was interacting with was from the upper social class. This pushed the interviewee to use the high-class variant. Moreover, it can be seen that [maa] is a common tool of negation that is used by all speakers of Jordanian dialects, preceded by a verb that can be suffixed or not, and this suffix [ish], however, carries a social meaning rather than lexical or a grammatical meaning. That is, it is linked with the middle class (fallahi) dialect, but the data show that many young male and female speakers from the middle class ignore using this variant and prefer to use the high-class variant [lisa maa verb] instead, as shown in the example above. This can be explained by the fact that the [ish] suffix is linked with an old-fashioned style, and consequently both young genders try to avoid it, and hence reformulate their identity in the high class rather than in their original middle class.

For the variants investigated in the study at both levels, it was found that the middle-class female speakers, regardless of their age and education use more variants of upper social class than their male counterparts. One explanation that the researcher would provide for this finding is that the middle-class females socialize with their high-class counterparts much more than the males do with speakers of the upper social class. One reason for that is that the middle-class females are more educated than their male counterparts. This is in fact attributed to the fact that not all males pursue their higher education and enroll in the army 
instead (where most of the army staff is from the middle-class people in Jordan) while females have no or very few positions in the army. This in turn forces them to pursue their education with the result that about two thirds of the population of each university in Jordan are females. Another important explanation of why middle-class females use more high-class variants than their male counterparts is that young females are much more vulnerable to criticism when they speak. That is, they would be criticized if they did not speak in a prestigious manner. Thus, they try to avoid variants that are considered less prestigious, like emphatic sounds or (-ish) suffixed negated verbs.

\section{Conclusion}

In the study, the social class serves as a motivation factor that pushes speakers to make new linguistic changes to adopt a new identity belonging to the high socioeconomic class by drawing on new language features (of upper class). Gender, age and education, in turn, are seen as important factors that affect or determine the extent to which the participants are triggered to make these changes to reformulate a new social identity in the new upper social class. The findings also corroborate what the researcher hypothesized that the young people (males and females) are more triggered to make linguistic changes than their aged counterparts, the females make more (vernacular) linguistic changes than the males at the phonetic level, but the difference between the two genders is not that big at the morphosyntactic level, and the educated people are more likely to make linguistic changes than the uneducated or less educated. Although the interviewers and the interviewees, who came from different social classes (from the upper class and middle class respectively), were expected to use diverging forms, the researcher found many examples that demonstrate that both speakers (the interviewer and the interviewee) produce more converging than diverging forms. This is attributed to the fact that the interviewees, particularly the females and young males, have a strong desire to reconstruct their identity in the upper class, and consequently they use or adopt variants of high-class people (like the interviewers') in Jordan. There is much more linguistic variation that is worth highlighting and investigating in Irbid city where the middle-class people live, and accordingly the researcher would echo what Labov concluded "members of the highest and lowest social groups tend not to change their pronunciation after it becomes fixed in adolescence but members of middle social groups sometimes do, possibly because of their social aspirations." (as cited in Wardhaugh \& Fuller, 2014. p.173).

\section{Future Research}

As the study did not employ any computer software program to analyze (phonetic) data to track and examine subtle or detailed differences between speakers, it would recommend using such programs as PRAAT to conduct acoustic analysis to find subtle differences that cannot be realized by ear. It is also recommended to conduct a larger study employing quantitative approach to test the data to examine if the differences between social groups are 
statistically significant or not. A larger study can be conducted where data are collected from different cities in Jordan to see if there are any significant differences with regards to changes that speakers make. Additionally, it recommends to conduct a study where different types of data (natural and controlled) are collected to investigate where people have more tendencies to make linguistic changes: in natural or controlled data.

\section{References}

Almbark, R. (2008). A sociophonetic study of emphasis in Syrian Arabic. MA thesis. The University of York.

Baranowski, M. (2013). Sociophonetics. In Bayley, R., Cameron, R., \& Lucas, C. (Eds.), The Oxford Handbook of Sociolinguistics. Oxford: Oxford University Press. pp. 403-424.

Cotter, W., \& Horesh, U. (2015). Social integration and dialect divergence in coastal Palestine. Journal of Sociolinguistics, 19, 460-483.

Cotter, W. (2016). A sociophonetic account of morphophonemic variation in Palestinian Arabic. Acoustical Society of America, 23, 1-9.

Embick, D. (2008). Variation and morphosyntactic theory: Competition fractionated. Language and Linguistics Compass, 2(1), 59-78.

Foulkes, P., Docherty, G. J., Khattab, G., \& Yaeger-Dror, M. (2010). Sound judgements: perception of indexical features in children's speech. In Preston, D. \& Niedzielski, N. (Eds.), A Reader in Sociophonetics. Berlin: De Gruyter. 327-356.

Hay, J., \& Drager, K. (2007). Sociophonetics. Annual Review of Anthropology, 36, 89-103.

Kaiser, E. (2011). Sociophonetics of Hmong American English in Minnesota. The university of Minnesota. PhD Dissertation.

Labov, W. (2006). A sociolinguistic perspective on sociophonetic research. Journal of Phonetics, 34(4), 500-515. https://doi.org/10.1016/j.wocn.2006.05.002

Podesva, R. (2006). Phonetic detail in sociolinguistic variation: its linguistic significance and role in the construction of social meaning. PhD thesis, Stanford University.

Sebregts, K. (2015). The sociophonetics and phonology of Dutch r. LOT. Utrecht university repository. The Netherlands.

Suleiman, S. (1985). Jordanian Arabic between diglossia and bilingualism: Linguistic analysis. John Benjamins Publishing Company: Amsterdam/Philadelphia.

Tucker, M. (2011). The morphosyntax of the Arabic verb: Toward a unified syntax-prosody. Linguistics Research Center, 177-211. Retrieved from https://escholarship.org/uc/item/0wx0s7qw 


\section{Macrothink}

Journal for the Study of English Linguistics

ISSN 2329-7034 2021, Vol. 9, No. 1

Wardhaugh, R., \& Fuller, J. (2014). An introduction to sociolinguistics. (7th ed.). WileyBlackwell.

\section{Copyright Disclaimer}

Copyright for this article is retained by the author(s), with first publication rights granted to the journal.

This is an open-access article distributed under the terms and conditions of the Creative Commons Attribution license (http://creativecommons.org/licenses/by/4.0/). 